\title{
Mapping conservation priorities and connectivity pathways under climate change for tropical ecosystems
}

\author{
Emily Fung ${ }^{1} \cdot$ Pablo Imbach $^{1} \cdot$ Lenin Corrales $^{1,2}$ • \\ Sergio Vilchez ${ }^{3} \cdot$ Nelson Zamora $^{4} \cdot$ Freddy Argotty $^{1}$. \\ Lee Hannah ${ }^{5}$ - Zayra Ramos 6 ,7
}

Received: 23 September 2015 /Accepted: 26 August 2016/Published online: 28 September 2016

(C) The Author(s) 2016. This article is published with open access at Springerlink.com

\begin{abstract}
Climate change and land use conversion are global threats to biodiversity. Protected areas and biological corridors have been historically implemented as biodiversity conservation measures and suggested as tools within planning frameworks to respond to climate change. However, few applications to national protected areas systems considering climate change in tropical countries exist. Our goal is to define new priority areas for biodiversity conservation
\end{abstract}

This article is part of a Special Issue on "Climate change impacts on ecosystems, agriculture and smallholder farmers in Central America" edited by Camila I. Donatti and Lee Hannah.

Electronic supplementary material The online version of this article (doi:10.1007/s10584-016-1789-8) contains supplementary material, which is available to authorized users.

Emily Fung

efung@catie.ac.cr

Nelson Zamora

zamoravn@gmail.com

Lee Hannah

1.hannah@conservation.org

Zayra Ramos

zramos@ catie.ac.cr

1 Environmental Modelling Laboratory, Climate Change Program, CATIE 7170, Turrialba 30501, Costa Rica

2 Latin University of Costa Rica, Heredia, Costa Rica

3 Biostatistics Unit, Graduate School, CATIE 7170, Turrialba 30501, Costa Rica

4 Botanical Department, National Biodiversity Institute (INBio), Heredia, Costa Rica

5 Center for Applied Biodiversity Science, Conservation International, Washington, DC 20037, USA

6 Climate Change Program, CATIE 7170, Turrialba 30501, Costa Rica

7 Department of Forest, Rangeland, and Fire Sciences, University of Idaho, Moscow, ID, USA 
and biological corridors within an existing protected areas network. We aim at preserving samples of all biodiversity under climate change and facilitate species dispersal to reduce the vulnerability of biodiversity. The analysis was based on a three step strategy: i) protect representative samples of various levels of terrestrial biodiversity across protected area systems given future redistributions under climate change, ii) identify and protect areas with reduced climate velocities where populations could persist for relatively longer periods, and iii) ensure species dispersal between conservation areas through climatic connectivity pathways. The study was integrated into a participatory planning approach for biodiversity conservation in Costa Rica. Results showed that there should be an increase of $11 \%$ and $5 \%$ on new conservation areas and biological corridors respectively. Our approach integrates climate change into the design of a network of protected areas for tropical ecosystems and can be applied to other biodiversity rich areas to reduce the vulnerability of biodiversity to global warming.

\section{Introduction}

Biodiversity supports the provision of ecosystem services contributing to human well-being (MEA 2005). Conserving samples of biodiversity are important for community and ecosystems structure and function and therefore to achieve environmental and development goals. Climate and land use change have been identified as the main global challenges to biodiversity conservation (Sala et al. 2000) due to effects on species distribution changes and extinctions, populations, structure and function of communities and ecosystems (Yang and Rudolf 2010). Protected areas (PA) and biological corridors (BC) have been proposed as conservation measures for biodiversity with particular relevance to face the impacts of climate change (Heller and Zavaleta 2009) accompanied by conservation planning frameworks and tools. However, few applications to national protected areas systems in tropical countries exist (Phillips et al. 2008; Game et al. 2011).

With over $50 \%$ of tropical forest already converted into agricultural lands or other uses (Hansen et al. 2013), the time-window for designing PA that can respond to the threat of climate change is shortening. The general principle, however, is clear: protection added in places that conserve species in both their present and future ranges can help meet current and future conservation targets (Araújo et al. 2004).

PA systems designed based on climate change effects on biodiversity may help respond to climate stressors. Multiple criteria have been used to identify climate-driven conservation gaps under the premise that biodiversity viability under future climate change can be achieved by preserving: i) terrestrial environmental gradients (Game et al. 2011), ii) climate refugia or holdouts to provide extended time for in-situ adaptation (Hannah et al. 2014), and iii) connectivity pathways for species dispersal movements (Game et al. 2011).

Coarse pattern characterization (i.e. ecosystems or biomes) of terrestrial biodiversity as well as environmental units defined by climatic and topographic variables have been used as surrogates of all biodiversity levels (communities, populations, species, genes) for conservation planning (Arponen et al. 2008; Game et al. 2011). Others have proposed the use of land systems or land facets, defined by a combination of homogeneous topography and soil variables, which are more stable factors over time (Beier et al. 2015). The assumption is that by covering a wide range of environmental conditions within a conservation network, the 
range of suitable living conditions is maximized, and therefore a comprehensive representation of species is protected (Arponen et al. 2008; Beier et al. 2015). Modeling of terrestrial vegetation redistribution under climate change has been conducted across the globe (Weltzin et al. 2003) but has been seldom used in conservation planning of protected areas (Hannah et al. 2007).

Spatial planning of protected areas for climate change may require to identify areas in which biodiversity responses to climate change may be minor (Hannah et al. 2014). The term refugia (or microrefugia) has been used referring to locations where species or populations survived the last glacial period (Ashcroft 2010; Dobrowski 2011). Recently, the concept has been applied to select areas that should be protected due to reduced impacts of climate change on biodiversity (Saxon 2008; Rull 2009). Tropical studies have focused on understanding late quaternary climate fluctuations and refugia dynamics of wet tropical forests (VanDerwal et al. 2009), to support conservation of amphibians (Puschendorf et al. 2009), and the role of riparian forests (Aide and Rivera 1998); although the Pleistocene refugia hypothesis of Haffer (1969) now seems thoroughly rejected (Carnaval et al. 2009). In contemporary human-induced climate change, continual warming will make return to a pre-existing climate rare or nonexistent. Refugia and microrefugia will therefore become vanishingly rare as climate change progresses (Hannah et al. 2014). Climate change holdouts refer to populations that may persist for longer but limited periods in localized areas, for example due to changes in climate that are smaller than regional trends (Dobrowski 2011; Keppel et al. 2012) and can improve the chances of successful species dispersal processes under future climate scenarios (Hannah et al. 2014).

Increasing landscape connectivity is broadly recommended as a climate change adaptation strategy for biodiversity conservation (Heller and Zavaleta 2009). The current design of the $\mathrm{BC}$ network in Mesoamerica is aimed at facilitating connectivity between protected areas (Mesoamericano 2007). However, species needs for dispersal pathways as a response to change in climate was not taken into account and current corridors have limited use for species dispersal under climate change (Imbach et al. 2013). Tropical areas pose a particular challenge for designing corridors given their species richness and limited knowledge on their dispersal processes (Rouget et al. 2006), although corridors with large areas that cover altitudinal gradients have been proposed as general design guidelines (Imbach et al. 2013).

Our goal was to identify and map potential gaps under the existing protected area system and design connectivity routes to facilitate species range shifts to reduce the vulnerability of biodiversity to a changing climate. Site selection was based on results from workshops with experts and modeling outputs. We modeled impacts on biodiversity based on a three step strategy: i) protect representative samples of various levels of terrestrial biodiversity (ecosystems, communities, populations and species) across protected area systems given future redistributions under climate change, ii) identify and protect areas with reduced climate velocities where populations could persist for relatively longer periods (referred as climate holdouts), and iii) ensure species dispersal between conservation areas through climatic connectivity pathways. Experts input was used to validate methods and to identify opportunities and constraints for field implementation of new conservation areas. The methods used here represents a participatory planning approach for biodiversity conservation under climate change in tropical areas based on Costa Rica as a case study. 


\section{Materials and methods}

\subsection{Study region}

Costa Rica is located in the Mesoamerican region near the northern limit of the Neotropical realm in a zone that begins the transition to the Nearctic realm of North America. Estimations show than in only $0.0001 \%$ of the earth's surface, the country holds around $4 \%$ (ca. 500,000) of all world's species (including all taxa) (ca. 14,000,000) (SINAC 2007). Costa Rica is part of the Mesoamerican biodiversity hotspot (Myers et al. 2000) and part of the Mesoamerican Biological Corridor, a network of PA and biological connectivity aimed at conserving large mammals and biodiversity along the length of Central America (DeClerck et al. 2010).

In response to rapid land use change during the 1970-1990s (3.7\% deforestation rate average for the period, Sanchez-Azofeifa et al. (2003)), the country started to consolidate the National System of Conservation Areas (SINAC) (SINAC 2007), increasing the extent of PA and BC from 3 to $26.5 \%$ of the country area (Estado de la Nación 2013). However, a few terrestrial environmental gradients (mountaintops of dry forests in Guanacaste and Osa peninsula, tropical montane vegetation and middle lowlands of the Nicoya Peninsula) are still not completely protected (Arias et al. 2008).

The first gap analysis of the PA system in Costa Rica aimed at ensuring that at least $90 \%$ of its biodiversity was under protection (García 1996). However, this assessment and the second to come in 2007, did not account for future climate change scenarios (SINAC 2007).

The first gap analysis used macro-types as the biodiversity surrogate, defined as landscape areas that share uniform physiognomic appearance and flora but did not consider vegetation associations (examples of macro-types classes include paramo, oak forests, evergreen/ deciduous forests). The classification was based on forest types, dominant species, soil type, elevation and geomorphology (1:250,000 scale, Gómez (1986)). Results suggested the need to extend the national conservation areas system to protect nine under-represented macro-types (García 1996). In 2007, the country repeated the gap analysis using an improved bioenvironmental gradient map describing phytogeographic units (PU) as a surrogate for biodiversity. The PU map consisted of 31 categories based on information from the earlier vegetation macro-types and floristic regions (Zamora 2008). The floristic regions refer to including floristic associations, based on dominant and indicator species (1:200,000 scale, Hammel et al. (2003)).

The 2007 gap analysis established to protect 10 to $30 \%$ (conservation targets) of each PU unit within the current PA system. Results from reserve network selection and expert knowledge, proposed to create 92 new conservation areas with approximately 712,000 ha and 128 new biological corridors between protected areas. The PU representativeness targets and current conservation network (PA and BC) (SINAC 2009) are used as the basis for the analysis presented here.

\subsection{General approach}

To design the PA and $\mathrm{BC}$ system for the long-term persistence of biodiversity under a changing climate, we integrated a spatial component addressing the impacts of climate change on biodiversity with considerations for field implementation of the proposed conservation areas. We used modeling tools and climate change scenarios to assess impacts, and participatory methods with experts for site selection. We addressed impacts on biodiversity by 
modeling: i) PU redistribution under future climate scenarios to quantify the ability of the current network of PA in protecting PUs under climate change, and ii) climate holdouts, mapped as sites with expected small changes in climate, relatively to its surrounding, assuming that their populations could then persist under climate change. We also mapped climatic connectivity routes for species dispersal between conservation areas assuming that dispersal pathways would follow climates relatively closer to their current ones. Modeling results were combined with information from experts, gathered during workshops, regarding threats and opportunities for field implementation of new conservation areas (Supplementary Material 1).

\subsubsection{Climate change scenarios}

We used climate data to model the current and future (under climate change scenarios) potential PU distributions, climate connectivity and holdout areas. Historical climate data was obtained from the WorldClim database at $\sim 1 \mathrm{~km}^{2}$ (30 arc-seconds) spatial resolution for the 1950-2000 period and used to model the current PU distribution using a statistical approach. To model future PU distribution, we used future climate scenarios from 19 General Circulation Models (GCMs) under the representative concentration pathway 4.5 (RCP 4.5, corresponding to an intermediate level of global radiative forcing) from CMIP5 (Coupled Model InterComparison Project 5, (IPCC 2013)) for the 2041-2060 period (Hijmans et al. 2005). To estimate both range distributions (current and future), 19 bioclimatic variables were derived from temperature and precipitation maps for each GCM run (Hijmans et al. 2005). Downscaling of climate scenarios was estimated by aggregating future anomalies, from GCM runs, to a high-resolution historical climatology (available at WorldClim.org).

\subsubsection{Terrestrial vegetation modeling}

We used the national PU map (1:500,000 scale) as a surrogate for biodiversity, defined as geographic areas sharing particular floristic vegetation patterns characterized by climate (temperature, precipitation and its seasonality), topography (relief), elevation and geology (Zamora 2008). The floristic vegetation pattern was defined as a type of vegetation were a group of indicator species coexist; given their abundancy, rarity or restricted distribution. Identification of indicator species was based on "keystone species": organisms controlling potential dominants, resource providers, mutualists and ecosystem engineers (Payton et al. 2002) based on available occurrence data. To develop the PU map, a multidisciplinary expert group (comprising biogeography, botany, climate, conservation, statistics, ecology, geology, geography, information technology and modeling scientists) worked on manually delineating each PU using indicator species, climate maps, contour lines and/or geographical features, such as rivers or basins. The resulting PU map was used during the 2007 (SINAC 2007) gap analysis and the one presented here. The PU map provides information suitable for a biodiversity coarse-filter assessment (Powell et al. 2000) that simplified experts and users familiarization, given its use in previous assessments.

We used a Random Forest algorithm (Liaw and Wiener 2002) to generate classification rules of the current distribution of the PU (Zamora 2008) using a combination of biophysical variables as predictors: i) five principal components (PC) capturing $90 \%$ of the variability from the 19 bioclimatic variables and evapotranspiration (Supplementary Material 2, Table 1) (Hijmans et al. 2005), ii) relief quantified as the topographic position index (Jenness 2006) 
from a digital elevation model (1 $\mathrm{km}^{2}$ pixel, Jarvis et al. (2008)) that classifies the landscape into slope position and landforms (plain, undulating, mountain and valleys and depressions) and iii) surface lithology describing age and origin of the rocks based on the national geological map (1:500,000 scale, USGS (1987)). Bioclimatic variables describe regional precipitation and temperature climatology at the annual, seasonal and monthly scales based on monthly mean values. Real evapotranspiration was based on Imbach et al. (2012). We used $70 / 30 \%$ of the pixels to train/validate the model that showed a misclassification rate of $11 \%$. The most important variables in the classification according to the Mean Decrease Accuracy were PC1, PC2, PC3 and surface lithology (Supplementary Material 2, Figure 1). A random forest model was used to predict the PU distribution under future climatic scenarios using the PC maps derived for each one of the 19 GCM's (Supplementary Material 2, Table 1). We considered future potential ecosystems presence on any given pixel, when $>66 \%$ of the future climate models (>13 out of $19 \mathrm{GCMs}$ ) showed agreement indicating a likely presence (according to IPCC 2013 guidelines).

Conservation targets were defined as a sub-set of species, communities or ecological systems that represent biodiversity, established for each PU during the 2007 gap analysis by expert's criteria, based on the area of each PU. Conservation targets were set of $>10,000$ ha or between 10 and $30 \%$ of the total area of each PU to be conserved to maintain a representative sample (SINAC 2007). We quantified the likely future area of each PU within protected areas. For those PU that did not meet conservation targets within PA, additional sites were selected with the Marxan planning support tool. Marxan is designed to solve problems when multiple complex solutions exist, by selecting sites that meet a specific conservation target with the most cost-efficient solution for field implementation (i.e. lowest cost) (Watts et al. 2009). A 250 ha hexagon was assumed to provide a minimum area useful for spatial planning and 21,180 planning units covered the country. In order to account for future uncertainties on PU distribution from climate scenarios, we estimated the contribution of each hexagon to achieve a PU conservation target as the product of each PU mean pixel frequency across the 19 scenarios by the total hexagon area. Therefore, our setup optimized the selection of additional conservation sites that maximized higher likelihood of PU presence under future climate scenarios. We assumed that conservation costs of a hexagon depended on its dominant land use (SINAC and FONAFIFO 2014), with forests having the lower cost for implementation (0) of conservation activities and non-forest areas (agriculture and urban areas) with maximum costs (100). Pastures, forest plantations and secondary forests were assigned costs of 60, 40 and 20 respectively. We calculated solutions with different clumping levels of planning units (Ball et al. 2009). PU without any significant likely future distribution $\left(<10 \mathrm{~km}^{2}\right)$, were not included in the analysis and assumed to disappear.

\subsubsection{Climate holdouts: velocity of climate change}

We mapped velocity of climate change as a proxy for climate holdouts to identify areas where populations may persist for longer periods. Velocity of climate change is calculated as the distance $(\mathrm{km})$ per year that a species would need to travel to maintain its original climate conditions (Loarie et al. 2009; Ackerly et al. 2010; Dobrowski et al. 2013). We estimated the velocity of climate change based on future changes in mean annual temperature and total annual precipitation following Loarie et al. (2009) and Dobrowski et al. (2013). We calculated velocity as the ratio of temporal (year/ $\mathrm{km}$ ) and 
spatial gradient $\left({ }^{\circ} \mathrm{C} / \mathrm{km}\right.$ or $\left.\mathrm{mm} / \mathrm{km}\right)$ of changes in climate, as a proxy for the potential speed at which species would need to disperse in the future. We mapped areas with minor velocities (arbitrarily selected as $<0.01{ }^{\circ} \mathrm{C} / \mathrm{km}$ ) assuming that species would need to move shorter distances to maintain its current climate and be able to persist for a relatively longer time. The resulting map was used to select conservation areas by experts during the participatory workshops.

\subsubsection{Climatic connectivity pathways: direction of climate change}

Climate change direction was used to identify possible spatial trajectories for species dispersal pursuing their suitable climate niche. We used the direction of future change in temperature (year $/ \mathrm{km}$ ), following Burrows et al. (2014) formula, to map the direction of potential trajectories. Burrows et al. 2014 combined trajectories to map corridor, sink, source, convergence and divergence areas. Nevertheless, we used a simplified approach based on each pixel direction of change. We assumed that all species have dispersal capacities to keep pace with climate change without accounting for species dispersal capacity nor potential barriers other than climatic. We assumed that continuous areas with similar direction represented connectivity pathways if the direction followed the shifts in the PU future redistribution, or a barrier otherwise. Clusters of vectors pointing at each other were also assumed as barriers. We assumed that the first situation (i.e. opposite direction) represented a larger barrier than the second (i.e. pointing to each other). Direction of changes in precipitation was not considered given its inconsistent direction pattern possibly resulting from uncertainty in future precipitation scenarios over this region (IPCC 2013).

\subsubsection{Conservation site and connectivity network selection: experts inputs}

Selection of additional conservation sites and BC resulted from combining results of experts input and modeling outputs during workshops. We systematized leading biologists and conservation planners opinion through participatory workshops. The first workshop focused on validating the methodologies. We started with a description on climate variability, trends and future climate scenarios as background to the analysis, followed by an open discussion based on guided questions (Supplementary Material 3) related to the methods, data availability and limitations. The second workshop aimed at communicating modeling results and identification of new gaps and connectivity routes. Working groups, comprising experts across regions of the country, were provided with base maps (of PA, BC, current conservation gaps and forest cover) and model outputs (PU future distribution, Marxan selected areas and climate holdouts). The climate change direction map was also used to design connectivity networks (Section 2.2.3). Maps were provided in transparent format allowing overlays to facilitate discussion. Experts provided criteria for site selection related to land use change threats (i.e., urban or cash crop developments, local community conflicts, other barriers for species -i.e., hydro-power reservoirs, stream contaminants) and opportunities for field implementation of new conservation areas (i.e., resources for implementation and community involvement). Site selection resulted from expert's consensus for each group while a rapporteur systematized implementation issues for each site discussed. The third workshop was oriented towards a broader audience (including previous workshops participants) to 
validate the final portfolio of new conservation areas and BC. Workshops attendance ranged between 15 and 31 experts.

\section{Results}

\subsection{Terrestrial vegetation modeling}

Future PUs distribution indicated that most will experience decrease in their likely distribution range (Fig. 1). The northern dry region, the humid southeast Caribbean slope and Talamanca's mountainside towards the Pacific lowlands did not present likely future distributions of any PU (grey areas of the map, Fig. 1). PU across the central mountain range (brown), Talamanca's Caribbean mountain range (green) and Pacific southernmost areas (light blue and orange) showed the greatest persistence areas under future scenarios (Fig. 1). PU from dryer northwestern areas (purple PU) experienced an increase in their future distribution range indicating an expansion into currently more humid areas. North Caribbean lowland plains (dark blue), Central Pacific lower slopes (red) and Talamanca's Caribbean mountain range (green) undergo a reduction of their current distribution combined with newly colonized areas (Fig. 1).

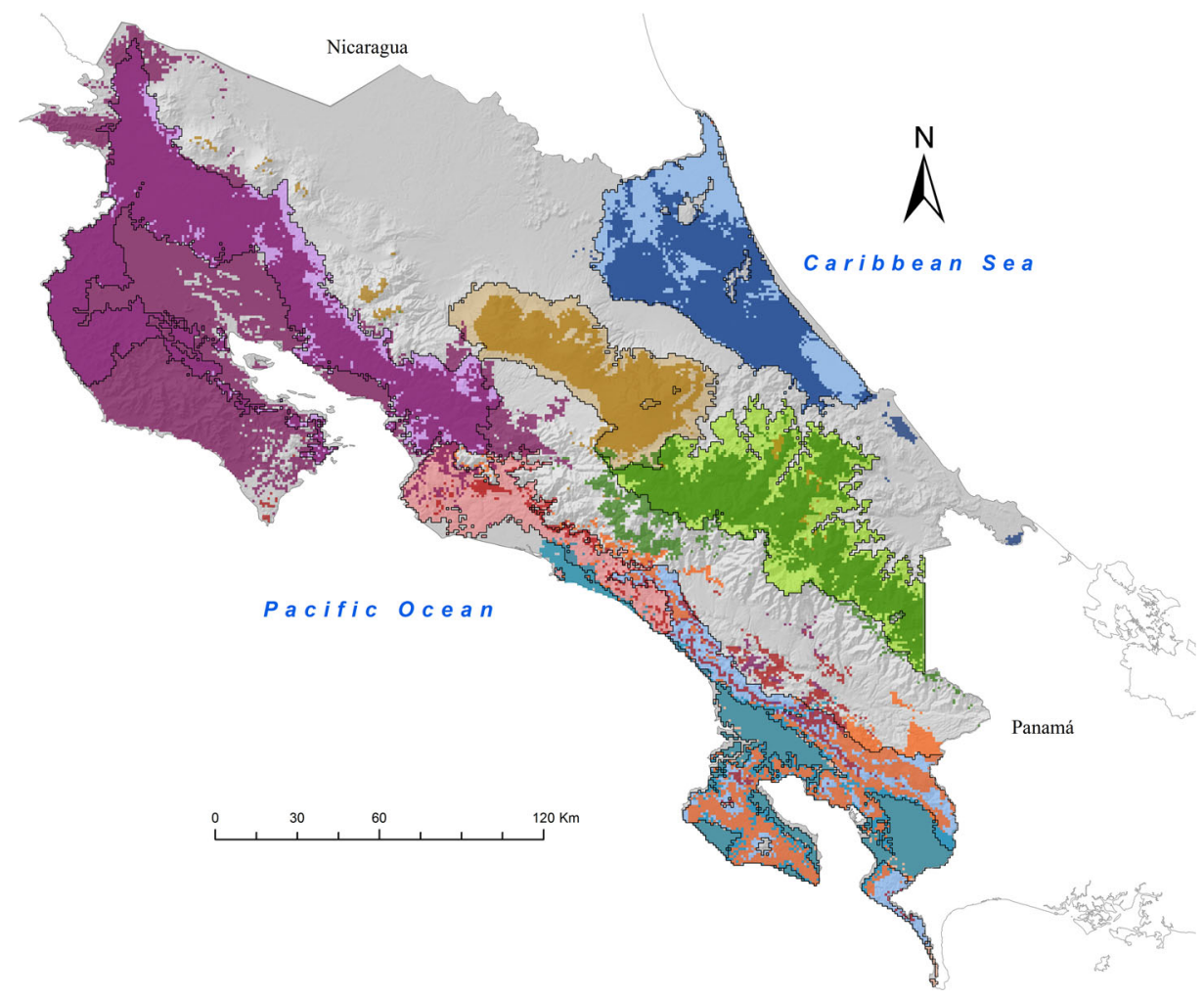

Fig. 1 Potential redistribution of phytogeographic units (PU) under future climate scenarios. Black lines delineate current PU distribution areas. Within the limits of each PU, light and dark color tones indicate the future loss and persistence areas respectively. Dark tones outside current PU boundaries indicate colonization areas 


\subsection{Climate holdouts: velocity of climate change}

The mean velocity for mean temperature and total precipitation for 2041-2060 across the country was $0.17 \mathrm{C}^{\circ} / \mathrm{km}$ and $0.88 \mathrm{~mm} / \mathrm{km}$ respectively. The highest velocity rates were observed in regions with low topographic relief, primarily found in the north and northeastern areas (Guanacaste and Alajuela provinces) for precipitation, in addition to the northwestern region (Caribbean floodplains in Tortuguero) for temperature. The lowest velocity rates were found in mountainous regions of the country. These potential holdouts were found in the central volcanic mountain range, central south mountains (La Amistad National Park) and mountains near the Pacific coast (Fig. 2).

\subsection{Climatic connectivity pathways}

Directional patterns appeared as i) continuous areas following the same direction demonstrating clear pathways for species dispersal and ii) undistinguishable pathways due to vectors pointing at each other. The country's complex topography resulted in pathways usually having a few arrows with opposite direction. Figure 3 shows examples of regional directional analysis from two sites in Costa Rica. Arrows indicate the direction of change in climate. Figure 3a-i shows the potential location of corridors (routes following the blue arrows) in areas with arrows pointing in the same direction as the range shift of a PU. Figure 3a-ii indicates a climate

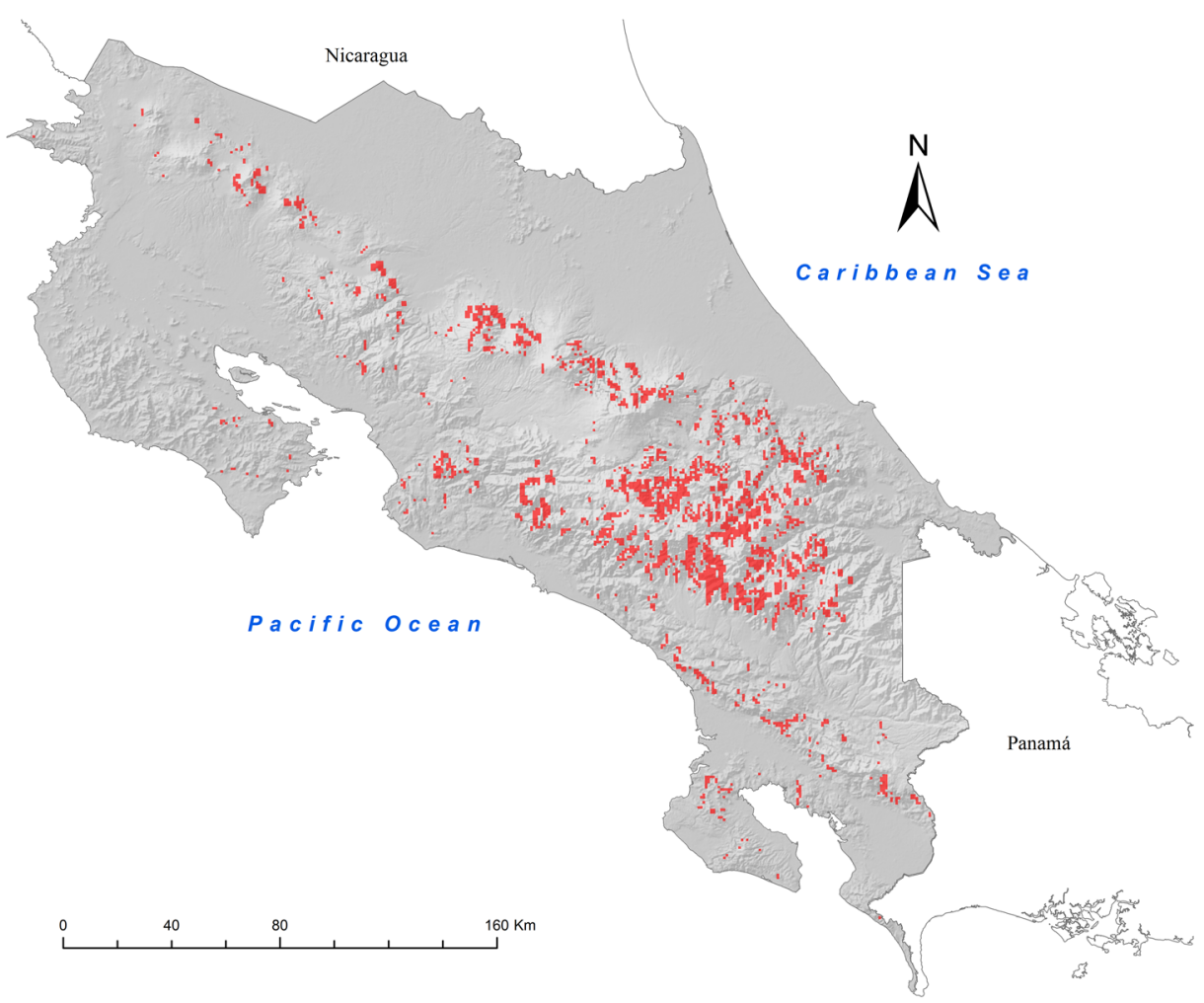

Fig. 2 Climate holdouts (red), estimated as the lowest temperature $\left({ }^{\circ} \mathrm{C} / \mathrm{km}\right)$ and precipitation $(\mathrm{mm} / \mathrm{km})$ velocities 
Fig. 3 Direction of annual temperature change under future climate scenarios. Purple, blue, yellow and green arrows indicate northeast, southeast, southwest and northwest directions of change respectively. Light and dark red areas indicate the current and future (persistence and colonization areas) distribution of a phytogeographic unit (PU). Black arrows indicate areas for proposed new climatic corridors and black circles show barriers. a The PU will likely experience a range reduction (dark red within its current distribution) and colonization areas (dark red pixels to the right outside its current distribution): i) blue arrows specify the climate direction that species might need to follow to colonize newly suitable areas, ii) yellow arrows exemplifies a climatic barrier for species dispersal with climate change in opposite direction as the course that follows the future distribution of the PU and, iii) all colored arrows cluster showing a barrier for dispersal. $\mathbf{b}$ the PU suffers a range reduction to smaller persistence areas within its current range (dark red) that require climate pathways to benefit species movement towards the persistence core (iv). The country topography is highly complex resulting in pathways usually having a few arrows contradicting the general landscape direction, therefore, we had to neglect single arrows barriers

barrier for species dispersal, as future re-distribution of the PU follows the opposite direction of climate change. Figure 3a-iii shows arrows in all directions exemplifying no clear pathways. Connectivity pathways were also identified to facilitate the contraction of PU. Figure 3b-iv shows the location of corridors that could favor PU range contractions (towards PU persistence over dark red pixels) and facilitate species dispersal towards persistence areas. We selected pathways benefiting the connectivity between biological corridors, protected areas and current conservation gaps (not shown in the figure).

\subsection{Conservation targets and gap analysis}

Future biodiversity distribution showed that: (i) 7 PUs had likely future areas in current protected areas that meet conservation targets, (ii) 10 PUs future distribution did not meet conservation targets, (iii) 4 PUs did not have any likely distribution area in the future and (iii) 10 PUs disappear under future climates. For the 10 PUs not achieving their conservation targets, we proposed 11 new conservation areas to maximize their representativeness under future scenarios. These PUs are located in the north and northwestern lowlands of the country (including one PU in the Pacific coast) and on the southern foothills of the Central Mountain Range.

Our results show an increase of 151,000 ha (11\% of the current extent) of new conservation areas and 237, 000 ha (5\% area increase from its current extent) in 15 new BC for Costa Rica, in order to increase biodiversity representativeness under climate change (Supplementary Material 4).

\section{Discussion}

Future expansions and contractions of PUs over the dry northwestern, Caribbean and central southern areas agree with other studies indicating redistribution of potential life zones (Bertrand et al. 2011; Khatun et al. 2013) and increased coverage of drier PU types (Imbach et al. 2012). These redistributions will result from migration of species or communities to track ideal climate conditions, with a range shift that generates colonization and contraction areas; persistence over current distribution through adaptation or extinction (Breshears et al. 2008). Resulting shifts in individual species responses will ultimately define the future composition of the PUs, requiring studies on species range redistributions, population and community dynamics. 


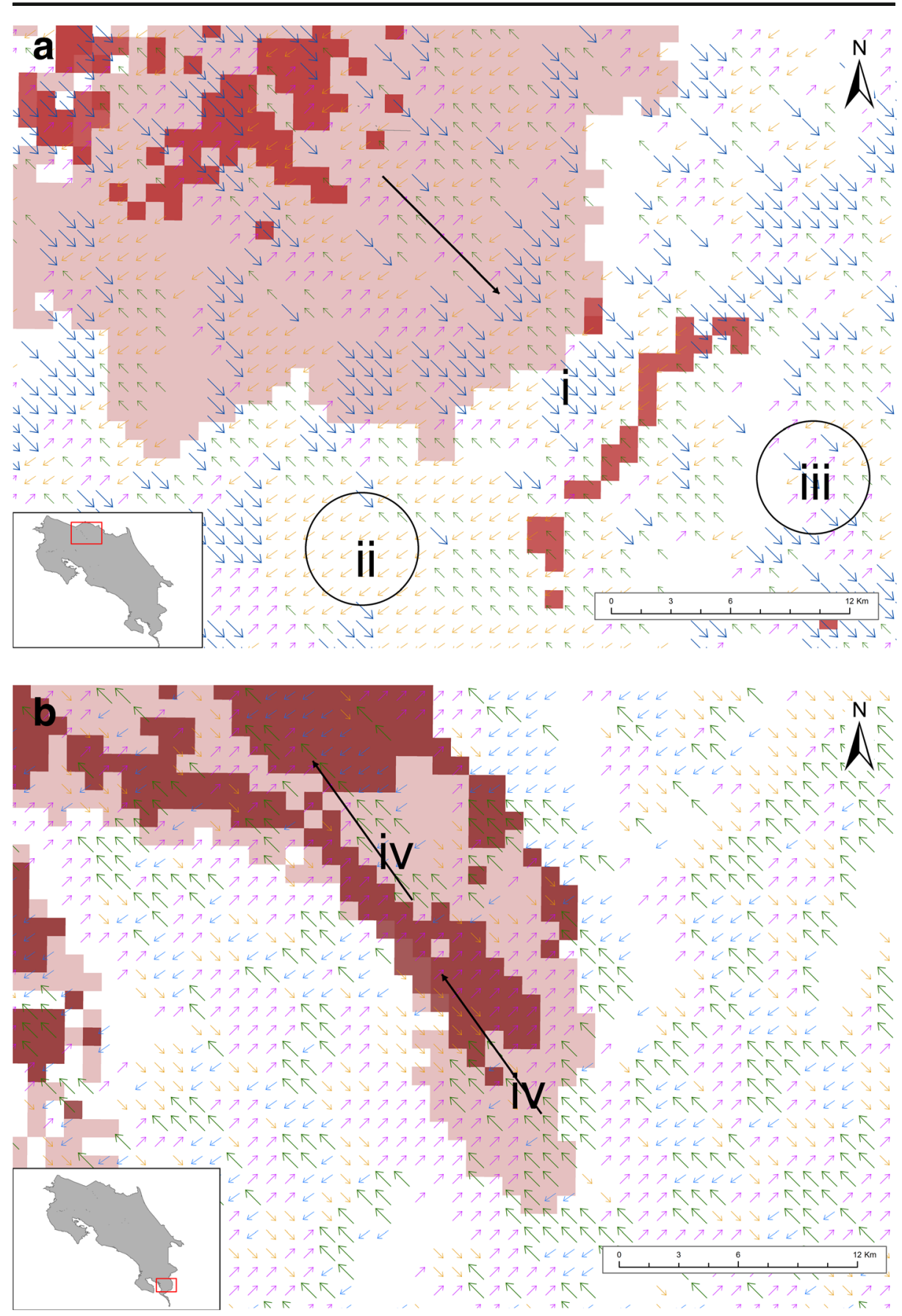

The Caribbean lowlands PUs (dark blue in Fig. 1), suggests new colonization areas over flatlands (towards the south) while the center south and pacific PUs (Green and red PU in Fig. 1) shift over mountain areas. Range shifts are expected to occur through pioneer species 
that disperse long distances and colonize by exponential population growth in less favorable climate conditions (Hampe and Petit 2005). Areas of the country without likely distribution of any PU (grey areas in Fig. 1), mostly resulting from GCM uncertainty or arrangement of novel climates, could lead to novel species assemblages (Bertrand et al. 2011).

Persistence areas were found in the central region of the country (brown and green PU, Fig. 1). The literature suggest that these PUs will retain species covering the inner part of the range distribution, as the margins suffer greater climate stress and experience a contraction (Hannah et al. 2014).

Mean annual temperature velocity estimates found in this study $(0.17 \mathrm{~km} / \mathrm{yr})$ are lower than those presented by Imbach et al. (2013) $(0.25 \mathrm{~km} / \mathrm{yr})$, Loarie et al. $(0.33 \mathrm{~km} / \mathrm{yr})$ and Burrows et al. (2014) (0.1-5 km/yr) for the Central American region, probably due to different emission scenarios, future time frames and finer spatial resolution of the approach. Dobrowski et al. (2013) calculated climate velocities at five different resolutions (between 30 arc-seconds and 1 degree) and found that at coarser spatial resolution climate velocity increased due to an underestimation on the terrain capacity to buffer changes in climate. We found no reports on precipitation velocities for this region. However, there is a general agreement pattern of higher temperature velocities in flatter areas and lower estimates over mountainous regions. Relatively small temperature changes over flat areas will require a species to disperse farther distances to track its ideal climate under changing conditions, while in mountainous regions, a short movement upslope or downslope will result in larger compensations, allowing the species to rapidly keep pace with changes in climate (Loarie et al. 2009; Imbach et al. 2013). Precipitation holdouts were also found in mountainous areas (over high slope areas). However, the relatively small anomalies of mean precipitation found might result from GCM positive and negative signals canceling each other, given the uncertainty on trends of future precipitation (Imbach et al. 2012). Its usefulness as a proxy for holdouts should be further explored.

The proposed BC should facilitate contractions or expansion of PU by allowing species to disperse to a suitable climate and rescue small populations from local extinction (due to demographic or environmental stochasticity) (Bull et al. 2007). Identification of holdout areas to support the design of $\mathrm{BC}$ provides for places where species may persist for longer periods and support species flow between the expansion and contraction areas. (Hannah et al. 2014). Temperature directions are dominated by the altitudinal gradient, since altitude is the main temperature controller over the region (Ackerly et al. 2010). Direction of precipitation showed no clear patterns, with contradicting directions at very small scales, limiting its use to define connectivity pathways.

Our conservation targets (10 to $30 \%$ of the PU area) are similar to those used for other studies (Langhammer et al. 2007), however, it would be valuable to explore the effect of different values or inclusion species level conservation targets. Furthermore, the methodology could benefit from improved representation of local species ecological characteristics including dispersal capacities and effects of landscape barriers to identify climate pathways or their sensitivity to changes in climate for improved holdouts mapping.

Experts and conservation managers were involved during all stages of the process to complement the systematic planning approach (Cowling et al. 2003). Their feedback, contributed to the selection of new biodiversity conservation sites and validation of the final portfolio. We found that expert knowledge provided for updated local level information hardly available on maps at national scale. Information referred to opportunities and barriers for implementation, socioeconomic aspects of the target area or micro areas of high endemism. Furthermore, their involvement potentially enhanced user's legitimacy of the conservation portfolio. 
Our results define new areas that could require landscape management for biodiversity conservation depending on their current vegetation cover and connectivity needs. These management activities can range from conservation or restoration of forests, agroforestry systems and live fences to removing barriers for dispersal, among others (Heller and Zavaleta 2009). Monitoring programs could prove useful to detect changes in areas of PU expansions and contractions in response to climate fluctuations, therefore strengthening our understanding on biodiversity response rates (Plattner 2009) and affected components (biomes, communities, populations, species and genes) (Bellard et al. 2012). Finally monitoring results could support future research and updates on the conservation portfolio.

\section{Conclusions}

We presented a multi-criteria approach for redesigning a network of conservation areas for enhancing long-term biodiversity viability under changing climate. The approach was based on integrating information on biodiversity distribution patterns, climate holdouts and connectivity pathways under future climate scenarios. A participatory planning process also accounted for expert knowledge on local context, potentially facilitating future implementation and improving legitimacy to the process. Results indicate the need for conservation activities on sites currently outside protected areas and for improved landscape connectivity across selected landscapes. However, assumptions regarding the use of phytogeographic units as surrogates for impacts on biodiversity or disregarding species dispersal capacity could have important implications for our findings. Future research and monitoring of changes in species, populations, communities and ecosystems should help fill these gaps. Finally, the resulting portfolio can support biodiversity conservation policies and the development of national adaptation strategies coherent with cross-country conservation efforts (Hannah et al. 2002). This multi-criteria approach, can be used in other regions to identify areas to ensure biodiversity conservation in face of climate change.

Acknowledgments This work was done to support "Costa Rica's adaptation of the biodiversity sector to climate change" project CR-T1081 ATN/OC-13260-CR coordinated by SINAC and partially financed by the Inter-American Development Bank (IDB). We acknowledge SINAC for their support during the process and all experts who provided their valuable input during workshops. We thank The Betty and Gordon Moore Center for Science at Conservation International for providing funds for open access. We thank Peter Läderach for his review of early versions of this manuscript.

Open Access This article is distributed under the terms of the Creative Commons Attribution 4.0 International License (http:/creativecommons.org/licenses/by/4.0/), which permits unrestricted use, distribution, and reproduction in any medium, provided you give appropriate credit to the original author(s) and the source, provide a link to the Creative Commons license, and indicate if changes were made.

\section{References}

Ackerly DD, Loarie SR, Cornwell WK, et al. (2010) The geography of climate change: implications for conservation biogeography. Divers Distrib 16:476-487. doi:10.1111/j.1472-4642.2010.00654.x

Aide TM, Rivera E (1998) Geographic patterns of genetic diversity in Poulsena armata (Moraceae): implications for teh theory of Pleistocene refugia and the importance of riparian forest. J Biogeogr 25:695-705 
Araújo MB, Cabeza M, Thuiller W, et al. (2004) Would climate change drive species out of reserves? An assessment of existing reserve-selection methods. Glob Chang Biol 10:1618-1626. doi:10.1111/j.13652486.2004.00828.x

Arias E, Chacón O, Induni G, et al. (2008) Identificación de vacíos en la representatividad de ecosistemas terrestres. Recur Nat y Ambient 54:21-27

Arponen A, Moilanen A, Ferrier S (2008) A successful community-level strategy for conservation prioritization. J Appl Ecol 45:1436-1445. doi:10.1111/j.1365-2664.2008.01513.x

Ashcroft MB (2010) Identifying refugia from climate change. J Biogeogr 37:1407-1413. doi:10.1111/j.13652699.2010.02300.x

Ball I, Possingham H, Watts M (2009) Marxan and relatives: software for spatial conservation prioritization. In: Spatial conservation prioritization: quatitative methods \& computational tools. Oxford University Press, Oxford

Beier P, Hunter ML, Anderson M (2015) Special section: conserving nature's stage. Conserv Biol 29:613-617. doi: $10.1111 /$ cobi.12511

Bellard C, Bertelsmeier C, Leadley P, et al. (2012) Impacts of climate change on the future of biodiversity. Ecol Lett 15:365-377. doi:10.1111/j.1461-0248.2011.01736.x

Bertrand R, Lenoir J, Piedallu C, et al. (2011) Changes in plant community composition lag behind climate warming in lowland forests. Nature 479:517-520. doi:10.1038/nature10548

Breshears DD, Huxman TE, Adams HD, et al. (2008) Vegetation synchronously leans upslope as climate warms. Proc Natl Acad Sci U S A 105:11591-11592. doi:10.1073/pnas.0806579105

Bull JC, Pickup NJ, Pickett B, et al. (2007) Metapopulation extinction risk is increased by environmental stochasticity and assemblage complexity. Proc Biol Sci 274:87-96. doi:10.1098/rspb.2006.3691

Burrows MT, Schoeman DS, Richardson AJ, et al. (2014) Geographical limits to species-range shifts are suggested by climate velocity. Nature 507:492-506. doi:10.1038/nature12976

Carnaval ACOQ, Hickerson MJ, Haddad CFB, et al. (2009) Stability predicts genetic diversity in the Brazilian Atlantic forest hotspot. Science 323:785-789. doi:10.1126/science.1166955

Cowling RM, Pressey RL, Sims-Castley R, et al. (2003) The expert or the algorithm?- comparison of priority conservation areas in the Cape Floristic region identified by park managers and reserve selection software. Biol Conserv 112:147-167. doi:10.1016/S0006-3207(02)00397-X

de la Nación E (2013) Vigésimo Informe Estado de la Nación en Desarrollo Humano Sostenible. San José, CR

DeClerck FAJ, Chazdon R, Holl KD, et al. (2010) Biodiversity conservation in human-modified landscapes of Mesoamerica: past, present and future. Biol Conserv 143:2301-2313. doi:10.1016/j.biocon.2010.03.026

Dobrowski SZ (2011) A climatic basis for microrefugia: the influence of terrain on climate. Glob Chang Biol 17: 1022-1035. doi:10.1111/j.1365-2486.2010.02263.x

Dobrowski SZ, Abatzoglou J, Swanson AK, et al. (2013) The climate velocity of the contiguous United States during the twentieth century. Glob Chang Biol 19:241-251. doi:10.1111/gcb.12026

Game ET, Lipsett-Moore G, Saxon E, et al. (2011) Incorporating climate change adaptation into national conservation assessments. Glob Chang Biol 17:3150-3160. doi:10.1111/j.1365-2486.2011.02457.x

García R (1996) Propuesta técnica de ordenamiento territorial con fines de conservación de biodiversidad. Costa Rica. Costa Rica, Informe de País

Gómez L (1986) Mapa de lo macrotipos de vegetación de Costa Rica. Serie de 10 mapas. Escala 1:250000. EUNED, San José, CR

Haffer J (1969) Speciation in Amazonian forest birds. Science 165:131-137. doi:10.1126/science.165.3889.131

Hammel BE, Grayum MH, Herrera C, Zamora N (2003) Manual of plants of Costa Rica, Volume II: gymnosperms and monocotyledons (Agavaceae-Musaceae). Missouri Botanical Garden Press, St. Louis

Hampe A, Petit RJ (2005) Conserving biodiversity under climate change: the rear edge matters. Ecol Lett 8:461467. doi:10.1111/j.1461-0248.2005.00739.x

Hannah L, Midgley GF, Lovejoy T, et al. (2002) Conservation of biodiversity in a changing climate. Conserv Biol 16:264-268. doi:10.1046/j.1523-1739.2002.00465.x

Hannah L, Midgley GF, Andelman S, et al. (2007) Protected area needs in a changing climate. Front Ecol Environ 5:131-138. doi:10.1890/1540-9295(2007)5[131:PANIAC]2.0.CO;2

Hannah L, Flint L, Syphard AD, et al. (2014) Fine-grain modeling of species' response to climate change: holdouts, stepping-stones, and microrefugia. Trends Ecol Evol 29:390-397. doi:10.1016/j. tree.2014.04.006

Hansen MC, Potapov PV, Moore R, et al. (2013) High-resolution global maps of 21st-century forest cover change. Science 342:850-853

Heller NE, Zavaleta ES (2009) Biodiversity management in the face of climate change: a review of 22 years of recommendations. Biol Conserv 142:14-32. doi:10.1016/j.biocon.2008.10.006

Hijmans RJ, Cameron SE, Parra JL, et al. (2005) Very high resolution interpolated climate surfaces for global land areas. Int J Climatol 25:1965-1978. doi:10.1002/joc.1276 
Imbach P, Molina L, Locatelli B, et al. (2012) Modeling potential equilibrium states of vegetation and terrestrial water cycle of Mesoamerica under climate change scenarios*. J Hydrometeorol 13:665-680. doi:10.1175/ JHM-D-11-023.1

Imbach P, Locatelli B, Molina LG, et al. (2013) Climate change and plant dispersal along corridors in fragmented landscapes of Mesoamerica. Ecol Evol 3:2917-2932. doi:10.1002/ece3.672

IPCC (2013) Climate change 2013: the physical science basis. In: Stocker TF, Qin D, Plattner G-K, Tignor M, Allen SK, Nauels JA, Xia Y, Bex V, Midgley PM (eds) The physical science basis, Contribution of Working Group I to the Fifth Assessment Report of the Intergovernmental Panel on Climate Change. University Press, Cambridge

Jarvis A, Reuter H, Nelson A, Guevara E (2008) Hole-filled seamless SRTM data V4. http://www.cgiar-csi.org/ data/srtm-90m-digital-elevation-database-v4-1. Accessed 12 Apr 2014

Jenness J (2006) Topographic Position Index (tpi_jen.avx) extension for ArcView 3.x, v. 1.3a. Jenness Enterprises. Available at: http://www.jennessent.com/arcview/tpi.htm

Keppel G, Van Niel KP, Wardell-Johnson GW, et al. (2012) Refugia: identifying and understanding safe havens for biodiversity under climate change. Glob Ecol Biogeogr 21:393-404. doi:10.1111/j.1466-8238.2011. 00686.x

Khatun K, Imbach P, Zamora J (2013) An assessment of climate change impacts on the tropical forests of Central America using the Holdridge Life Zone (HLZ) land classification system. iForest - Biogeosciences For 6: 183-189

Langhammer PF, Bakarr MI, Bennun LA, et al. (2007) Identification and gap analysis of key biodiversity areas: targets for comprehensive protected area systems. Gland, Switzerland

Liaw A, Wiener M (2002) Classification and regression by random forest. R News 2:18-22. doi:10.1177/ 154405910408300516

Loarie SR, Duffy PB, Hamilton H, et al. (2009) The velocity of climate change. Nature 462:1052-1055. doi:10. 1038/nature08649

MEA (Millenium Ecosystem Assessment) (2005) Ecosystems and human well-being: synthesis. Island Press, Washington, DC

Mesoamericano PCB (2007) Informe final proyecto establecimiento de un Programa para la consolidación del Corredor Biológico Mesoamericano. Managua, Nicaragua

Myers N, Fonseca GAB, Mittermeier RA, et al. (2000) Biodiversity hotspots for conservation priorities. Nature 403:853-858. doi:10.1038/35002501

Payton IJ, Fenner M, Lee WG (2002) Keystone species: the concept and its relevance for conservation management in New Zealand. Sci Conserv 203:5-29. doi:10.1186/1472-6785-4-10

Phillips SJ, Williams P, Midgley G, Archer A (2008) Optimizing dispersal corridors for the cape proteaceae using network flow. Ecol Appl 18:1200-1211. doi:10.1890/07-0507.1

Plattner G-K (2009) Climate change: terrestrial ecosystem inertia. Nat Geosci 2:467-468

Powell GVN, Barborak J, Rodriguez SM (2000) Assessing representativeness of protected natural areas in Costa Rica for conserving biodiversity: a preliminary gap analysis. Biol Conserv 93:35-41. doi:10.1016/S00063207(99)00115-9

Puschendorf R, Carnaval AC, Vanderwal J, et al. (2009) Distribution models for the amphibian chytrid Batrachochytrium dendrobatidis in Costa Rica: proposing climatic refuges as a conservation tool. Divers Distrib 15:401-408. doi:10.1111/j.1472-4642.2008.00548.x

Rouget M, Cowling RM, Lombard AT, et al. (2006) Designing large-scale conservation corridors for pattern and process. Conserv Biol 20:549-561. doi:10.1111/j.1523-1739.2006.00297.x

Rull V (2009) Microrefugia. J Biogeogr 36:481-484. doi:10.1111/j.1365-2699.2008.02023.x

Sala OE, Chapin FS, Armesto JJ, et al. (2000) Global biodiversity scenarios for the year 2100. Science 287: 1770-1774. doi:10.1126/science.287.5459.1770

Sanchez-Azofeifa G, Daily G, Pfaff A, Busch C (2003) Integrity and isolation of Costa Rica's national parks and biological reserves:examining the dynamics of land-cover change. Biol Conserv 109:123-135

Saxon E (2008) Noah's parks: a partial antidote to the Anthropocene extinction event. Biodiversity 9:5-10. doi: 10.1080/14888386.2008.9712901

SINAC (Sistema Nacional de Áreas de Conservación Costa Rica) (2007) GRUAS II: Propuesta de Ordenamiento Territorial para la conservación de la biodiversidad de Costa Rica, vol 1. SINAC, San José

SINAC (2009) Corredores Biológicos [mapa]. 1: 50 000. San José: Sistema Nacional de Áreas de Conservación. Shapefile.

SINAC, FONAFIFO (2014) Tipos de bosque de Costa Rica, Inventario Nacional Forestal (database). Sistema Nacional de Áreas de Conservación, Ministerio de Ambiente y Energía y Fondo Nacional de Financiamiento Forestal, San José

USGS (1987) Geology and Resource Assessment of Costa Rica [map]. 1:500,000. USGS: U.S. Geological Survey 
VanDerwal J, Shoo LP, Williams SE (2009) New approaches to understanding late quaternary climate fluctuations and refugial dynamics in Australian wet tropical rain forests. J Biogeogr 36:291-301. doi:10.1111/j. 1365-2699.2008.01993.x

Watts ME, Ball IR, Stewart RS, et al. (2009) Marxan with zones: software for optimal conservation based landand sea-use zoning. Environ Model Softw 24:1513-1521. doi:10.1016/j.envsoft.2009.06.005

Weltzin JF, Loik ME, Schwinning S, et al. (2003) Assessing the response of terrestrial ecosystems to potential changes in precipitation. Bioscience 53:941. doi:10.1641/0006-3568(2003)053[0941:ATROTE]2.0.CO;2

Yang LH, Rudolf VHW (2010) Phenology, ontogeny and the effects of climate change on the timing of species interactions. Ecol Lett 13:1-10. doi:10.1111/j.1461-0248.2009.01402.x

Zamora N (2008) Unidades Fitogeográficas para la clasificación de ecosistemas terrestres en Costa Rica. Recur Nat y Ambient 54:14-20 